\title{
Comprehensibility ratings of concrete and abstract sentences
}

\author{
EDWARD J. ROWE \\ Memorial University of Newfoundland, St. John's, Newfoundland, Canada A1C 5S7 \\ and \\ BRYCE SCHURR and DENNIS MEISINGER \\ University of Alberta, Edmonton, Alberta, Canada T6G $2 \mathrm{~J} 8$
}

\begin{abstract}
Comprehensibility ratings are given for 54 concrete and 54 abstract sentences written as actives, passives, and interrogatives. Analysis of the ratings showed that the concrete sentences were easier to understand than the abstract sentences, but all three sentence forms were equally comprehensible.
\end{abstract}

A number of recent investigations have examined the effect of concreteness on the retention of prose material. In agreement with the results of research using individual words, these studies suggest that concrete, easily imaged sentences or prose passages are remembered better than corresponding material of more abstract content. This difference has been attributed to the greater ease of storing concrete material in a highly memorable form as visual images (Paivio, 1971).

However, Johnson, Bransford, Nyberg, and Cleary (1972) have pointed out that concrete sentences, in addition to being more imageable, are also easier to comprehend than abstract sentences. This difference in ease of comprehension, observed with both reaction time measures (Holmes \& Langford, 1976; Klee \& Eysenck, 1973) and subjective ratings (Johnson et al., 1972; Kuiper \& Paivio, 1977) confounds an imagery interpretation of retention differences between concrete and abstract material. Consequently, researchers exploring the concreteness factor in sentence memory have attempted to equate concrete and abstract sentences for comprehensibility (Kuiper \& Paivio, 1977; Moeser, 1974, 1975).

The present report makes available a set of concrete and abstract sentences that have been scaled for comprehensibility in each of three forms: active, passive, and interrogative. While research to date has concentrated on active sentences, these materials will also provide an opportunity to examine concreteness and comprehension factors in memory for passives and interrogatives.

This research was supported in part by a grant to Edward J. Rowe from the National Research Council of Canada. Lee Ann Montgomery assisted in the data analysis. Bryce Schurr's present address is Headquarters Business Development Department, Bell Canada, 16th Floor, 220 Laurier, Ottawa, Canada.

\section{METHOD}

\section{Materials}

The initial pool of items consisted of 108 sentences in the active voice of the form "The (adjective) (noun) (verb) (article) (adjective) (noun)." One hundred of the sentences (50 concrete and 50 abstract) were those used by Begg and Paivio (1969), and details on their construction may be obtained from that study. Four additional concrete and abstract sentences were constructed by a similar method. Each of the sentences, which are listed in the Appendix to this report, was rewritten in the passive and interrogative voice. For example, the active sentence, "The vicious dog attacked the helpless man," was rewritten as "The helpless man was attacked by the vicious dog" in the passive voice and "Did the vicious dog attack the helpless man?" as an interrogative. Minor alterations in the wording of a few of the transformed sentences (i.e., substituting "the" for "a") were necessary in order to make them more meaningful as judged by the authors. The complete set of 324 sentences is available on request.

Three sets of 108 sentences each were drawn from the pool of 324 , with an equal number of actives, passives, and interrogatives in each set. One-half of the sentences of each form were concrete and one-half abstract. The sentences in each set were unique, but each sentence was represented in each of its three versions across all three sets. The order of items within each set was randomized for presentation to the subjects, but the alternate forms of each sentence occurred in the same ordinal position in the three sets.

\section{Procedure}

The subjects were given the following instructions: "I'm going to read aloud a number of sentences, one at a time. For each sentence that I read, I want you to decide how easy you think the sentence is to understand or comprehend. You give your answer by circling one of the numbers in the appropriate line on the answer sheet. If you can easily understand the meaning of a sentence, circle 7 for that sentence. If you find a sentence very hard to understand, circle 1 . Use the remaining numbers between 1 and 7 to indicate your reaction to sentences that are intermediate in difficulty." The sentences were read to the subjects at a rate of one every $10 \mathrm{sec}$, with a rest period of about 3 min halfway through the set. 


\section{Subjects}

Each set of sentences was rated by a group of paid volunteers from undergraduate psychology classes at Memorial University, with 17,18 , and 20 subjects in the three groups.

\section{RESULTS AND DISCUSSION}

The mean comprehension rating for each sentence appears in the Appendix. The mean of these means was calculated for each of the six sentence types. For the concrete sentences, the overall mean ratings were 6.40 for actives, 6.40 for passives and 6.37 for interrogatives, with standard deviations of $.62, .63$, and .66 , respectively. The abstract sentences produced ratings of 5.58 for actives, 5.43 for passives, and 5.49 for interrogatives, with standard deviations of $.80, .87$, and .86 . The mean ratings for the 54 sentences of each type were used as the cell entries in an analysis of variance of rated comprehension. The analysis showed a significant effect of concreteness $[\mathrm{F}(1,318)=115, \mathrm{p}<.001, \mathrm{MSe}=.56]$, but no significant effect of syntactic form, and a nonsignificant interaction.

Product-moment correlation coefficients were also calculated on the ratings for actives, passives, and interrogatives, separately for concrete and abstract sentences. For the concrete sentences, the ratings for actives and passives were correlated .81 , actives and interrogatives were correlated .81 , and passives and interrogatives .76. For the abstract sentences, the correlation between actives and passives was .68 , with a correlation of .74 for actives and interrogatives and also for passives and interrogatives.

In agreement with previous research (Johnson et al., 1972; Kuiper \& Paivio, 1977), the concrete sentences were easier to comprehend than the abstract sentences. Marschark and Paivio (1977, Experiment 3) have reported some data that seem to be discrepant with these results. They had subjects rate the "meaningfulness" or ease of understanding of a set of sentences of the same form as the abstracts used here, and found no difference between the ratings of concrete and abstract items. However, they also included a sample of anomalous sentences as part of the rated set. These items may have inflated the ratings for abstract sentences and obscured any effect of the concreteness variable. The procedure used here and in the studies of Johnson et al. (1972) and Kuiper and Paivio (1977), where no anomalous sentences were included, is probably more sensitive to differences in comprehensibility.

Interestingly, Marschark and Paivio (1977, Experiments 1 and 2) also found that, compared to the rated imagery of sentences, comprehensibility was a minor factor in recall. Imagery was more highly correlated with cued recall scores than comprehensibility, and the correlation between comprehensibility and recall was not significant when the effect of imagery was partialed out. Thus the difference in comprehensibility between concrete and abstract sentences may be a manifestation of their imagery properties, a point which remains to be substantiated by further research.

\section{REFERENCES}

Begg, I., \& Paivio, A. Concreteness and imagery in sentence meaning. Journal of Verbal Learning and Verbal Behavior, $1969,8,821-827$.

Holmes, V. M., \& LANGFoRd, J. Comprehension and recall of abstract and concrete sentences. Journal of Verbal Learning and Verbal Behavior, 1976, 15, 559-566.

Johnson, M. K., Bransford, J. D., Nyberg, S. E., \& Cleary, J. J. Comprehension factors in interpreting memory for abstract and concrete sentences. Journal of Verbal Learning and Verbal Behavior, 1972, 11, 451-454.

KLEe, H., \& Eysenck, M. W. Comprehension of abstract and concrete sentences. Journal of Verbal Learning and Verbal Behavior, 1973, 12, 522-529.

Kuiper, N. A., \& Paivio, A. Incidental recognition memory for concrete and abstract sentences equated for comprehensibility. Bulletin of the Psychonomic Society, 1977, 9, 247-249.

Marschark, M., \& Paivio, A. Integrative processing of concrete and abstract sentences. Journal of Verbal Learning and Verbal Behavior, 1977, 16, 217-231.

MoEser, S. D. Memory for meaning and wording in concrete and abstract sentences. Journal of Verbal Learning and Verbal Behavior, 1974, 13, 682-697.

MoESER, S. D. Memory for language organization in concrete and abstract sentences. Memory \& Cognition, 1975, 3, 560-568.

PaIvio, A. Imagery and verbal processes. New York: Holt, Rinehart, \& Winston, 1971.

(Received for publication October 14, 1977.)

\begin{tabular}{|c|c|c|c|}
\hline & \multicolumn{3}{|c|}{ Form } \\
\hline & Active & Passive & Interrogat \\
\hline \multicolumn{4}{|l|}{ Concrete Sentences } \\
\hline The crippled juggler sported a gaudy costume. & 6.00 & 5.00 & 5.94 \\
\hline The savage storm flattened a beautiful flower. & 7.00 & 7.00 & 6.12 \\
\hline The sharp arrow pierced a frantic bird. & 5.94 & 6.76 & 6.56 \\
\hline The delicate maiden watched a golden sunset. & 6.88 & 6.61 & 6.65 \\
\hline The friendly banker purchased a blue automobile. & 7.00 & 7.00 & 6.94 \\
\hline The arrogant gentleman smoked a rancid cigar. & 5.39 & 5.24 & 5.35 \\
\hline The caustic prosecutor accused a frightened prisoner. & 5.47 & 5.71 & 4.78 \\
\hline The fidgety wife folded a crinkled new spaper. & 6.44 & 6.82 & 7.00 \\
\hline The vindictive teacher slapped a helpless boy. & 5.06 & 5.71 & 5.12 \\
\hline
\end{tabular}




\begin{tabular}{|c|c|c|c|}
\hline & \multicolumn{3}{|c|}{ Form } \\
\hline & Active & Passive & Interrogative \\
\hline The destructive army pillaged a prosperous village. & 5.47 & 5.35 & 5.94 \\
\hline The brutal officer snapped an abrupt salute. & 6.82 & 5.59 & 6.39 \\
\hline The talkative admiral attended a costume party. & 7.00 & 6.56 & 6.71 \\
\hline The pompous monarch married a triumphant queen. & 5.47 & 5.56 & 4.82 \\
\hline The active volcano destroyed a majestic forest. & 6.83 & 6.76 & 6.59 \\
\hline The reckless baron flipped a shining coin. & 6.47 & 6.47 & 6.33 \\
\hline The beautiful woman picked a white daisy. & 6.94 & 7.00 & 7.00 \\
\hline The wonderful gift preceded the exciting kiss. & 6.82 & 6.94 & 6.24 \\
\hline The bright headlight illuminated the gloomy street. & 6.67 & 6.88 & 6.71 \\
\hline The jagged stone shattered a clear window. & 7.00 & 6.94 & 6.64 \\
\hline The rolling hillside surrounded a muddy valley. & 6.61 & 6.88 & 6.88 \\
\hline The stubborn proprietor opened an expensive restaurant. & 6.00 & 6.17 & 5.94 \\
\hline The cheerful artist entertained a lonely damsel. & 6.82 & 6.61 & 6.82 \\
\hline The loving mother served an excellent family. & 6.59 & 6.24 & 6.44 \\
\hline The strong policeman ousted a seedy beggar. & 5.18 & 5.47 & 5.67 \\
\hline The white foam topped a restless sea. & 6.33 & 6.94 & 5.18 \\
\hline The impulsive builder decorated a stylish cottage. & 5.94 & 5.78 & 5.82 \\
\hline The young singer caressed a pretty girl. & 6.78 & 6.71 & 6.35 \\
\hline The greedy attendant devoured a soft pudding. & 6.47 & 6.71 & 6.61 \\
\hline The muscular blacksmith lifted a bulky hammer. & 6.90 & 6.88 & 6.94 \\
\hline The bright light blinded a small rabbit. & 6.94 & 7.00 & 7.00 \\
\hline The fat woman polished a red apple. & 6.82 & 6.85 & 7.00 \\
\hline The dynamic lecturer captivated an energetic committee. & 4.94 & 6.06 & 5.80 \\
\hline The hallow tomb housed a decaying corpse. & 5.95 & 5.88 & 6.06 \\
\hline The buoyant steamer sailed a tossing sea. & 6.35 & 5.76 & 6.30 \\
\hline The noisy priest amused a lively infant. & 6.47 & 6.95 & 6.65 \\
\hline The clumsy dog broke the valuable vase. & 6.90 & 6.94 & 7.00 \\
\hline The falling rock killed a sinful captive. & 6.29 & 6.59 & 6.80 \\
\hline The colorful snake crushed a screaming beast. & 6.94 & 6.85 & 6.65 \\
\hline The poor musician played a rusty trumpet. & 6.80 & 6.76 & 7.00 \\
\hline The aggressive settler felled an immense tree. & 6.50 & 5.94 & 6.35 \\
\hline The vicious hound chased a wild animal. & 6.88 & 6.94 & 6.95 \\
\hline The skillful doctor soothed a flaming sunburn. & 6.65 & 6.82 & 7.00 \\
\hline The old professor occupied a comfortable seat. & 7.00 & 6.94 & 6.95 \\
\hline The raging elephant trampled an orderly caravan. & 5.65 & 5.70 & 6.47 \\
\hline The spirited leader slapped the mournful hostage. & 6.40 & 6.29 & 6.24 \\
\hline The enthusiastic painter sketched the ancient temple. & 6.95 & 6.41 & 6.82 \\
\hline The tortured slave uttered a deafening shriek. & 6.65 & 6.95 & 6.65 \\
\hline The polite child presented an aromatic bouquet. & 5.29 & 5.18 & 5.60 \\
\hline The raging fire gutted a condemned building. & 6.76 & 6.82 & 6.95 \\
\hline The alert fisherman swatted a buzzing mosquito. & 6.94 & 6.60 & 6.82 \\
\hline The offensive performer cheered a zealous speaker. & 4.90 & 4.53 & 4.24 \\
\hline The rickety stagecoach crossed a winding river. & 6.60 & 6.53 & 6.59 \\
\hline The rich physician carried a black umbrella. & 6.85 & 6.88 & 6.71 \\
\hline The carefree student climbed a high tower. & 6.71 & 6.94 & 6.95 \\
\hline \multicolumn{4}{|l|}{ Abstract Sentences } \\
\hline The rural community insured a deprived childhood. & 6.53 & 5.67 & 5.47 \\
\hline The indecisive argument depressed a waiting group. & 6.39 & 5.88 & 5.39 \\
\hline The solemn creed encouraged an excessive devotion. & 3.94 & 4.12 & 3.78 \\
\hline The actual quotation lacked a rational foundation. & 5.59 & 4.50 & 5.76 \\
\hline The constant hope endured an attempted extinction. & 4.12 & 5.83 & 3.65 \\
\hline The popular view raised a considerable discrepancy. & 4.83 & 4.24 & 4.17 \\
\hline The recent speculation provided an acceptable solution. & 5.94 & 6.41 & 6.33 \\
\hline The revised procedure facilitated an expected outcome. & 4.89 & 4.29 & 4.76 \\
\hline The strict requirements hindered a large attendance. & 6.44 & 6.18 & 5.65 \\
\hline The remaining duty involved a standard payment. & 5.71 & 5.12 & 5.39 \\
\hline The free country organized a private venture. & 5.53 & 6.41 & 6.00 \\
\hline The national election indicated a secure future. & 6.24 & 6.17 & 6.76 \\
\hline The dull description constituted a boring chapter. & 6.47 & 6.28 & 6.29 \\
\hline The annual report recommended a complete renovation. & 6.83 & 5.65 & 6.35 \\
\hline The available literature cited a useful article. & 6.24 & 5.18 & 5.61 \\
\hline The stark truth created a chaotic condition. & 5.41 & 4.53 & 5.00 \\
\hline The absolute faith aroused an enduring interest. & 5.29 & 4.33 & 4.59 \\
\hline The analytic view maintained an objective position. & 3.67 & 4.00 & 4.71 \\
\hline
\end{tabular}




\begin{tabular}{|c|c|c|c|}
\hline & \multicolumn{3}{|c|}{ Form } \\
\hline & Active & Passive & Interrogative \\
\hline The unfair attitude destroyed a promising idea. & 6.53 & 6.82 & 6.50 \\
\hline The entire episode prefaced a foreign affair. & 4.72 & 4.18 & 4.59 \\
\hline The unpleasant atmosphere replaced a dismal silence. & 6.29 & 6.22 & 5.12 \\
\hline The mistaken assumption preserved a naive rationale. & 4.00 & 3.44 & 3.35 \\
\hline The plausible address answered a contradictory reply. & 4.94 & 5.18 & 4.72 \\
\hline The limited text explained the complicated formula. & 6.41 & 6.53 & 6.22 \\
\hline The close supervision guaranteed a strict obedience. & 6.44 & 6.76 & 6.65 \\
\hline The mediocre demonstration inspired a select few. & 3.76 & 4.56 & 4.35 \\
\hline The extensive investigation furnished a reasonable criticism. & 5.94 & 5.76 & 6.45 \\
\hline The strange mistake altered an established conclusion. & 6.47 & 6.05 & 5.76 \\
\hline The habitual behavior acquired a noble quality. & 5.20 & 4.76 & 4.65 \\
\hline The stray prejudice revealed an ugly nature. & 5.18 & 5.35 & 5.65 \\
\hline The former custom abused a moral principle. & 5.41 & 6.20 & 5.71 \\
\hline The final decision nullified a prior commitment. & 5.41 & 6.05 & 5.59 \\
\hline The preliminary hypothesis predicted an unstable relationship. & 6.25 & 4.88 & 4.88 \\
\hline The latest evidence suggested an alternative version. & 5.88 & 5.76 & 6.50 \\
\hline The current effort concluded a productive program. & 5.47 & 5.55 & 5.59 \\
\hline The horrible fear followed a traumatic experience. & 5.40 & 4.00 & 5.29 \\
\hline The early civilization organized a feudal system. & 5.65 & 6.41 & 6.20 \\
\hline The impartial source identified a hidden fault. & 5.76 & 5.50 & 5.24 \\
\hline The plain alteration introduced an essential balance. & 4.45 & 4.41 & 4.83 \\
\hline The tentative reason supplied an adequate explanation. & 5.05 & 5.06 & 5.06 \\
\hline The arbitrary regulation provoked a civil complaint. & 4.65 & 4.47 & 5.20 \\
\hline The main assembly noticed an unnatural pause. & 6.29 & 6.41 & 6.70 \\
\hline The thrifty business registered an average profit. & 6.47 & 5.85 & 6.24 \\
\hline The careful study resolved an open question. & 6.59 & 6.45 & 5.76 \\
\hline The passive majority defeated a listless opposition. & 5.40 & 4.47 & 4.06 \\
\hline The vague notion survived a renewed concern. & 5.05 & 4.88 & 4.76 \\
\hline The additional fact settled a major disagreement. & 6.06 & 6.65 & 6.65 \\
\hline The original location fulfilled a customary requirement. & 5.76 & 4.76 & 6.40 \\
\hline The previous calculation contributed a significant result. & 6.12 & 5.53 & 6.75 \\
\hline The last crisis created a real necessity. & 4.76 & 6.30 & 6.12 \\
\hline The introductory statement promised a logical treatment. & 6.00 & 5.65 & 5.76 \\
\hline The awkward incident prevented a possible agreement. & 6.06 & 6.45 & 6.24 \\
\hline The advanced technology obtained a respectable reputation. & 5.90 & 5.35 & 5.94 \\
\hline The minor change modified a basic measure. & 5.35 & 5.71 & 5.30 \\
\hline
\end{tabular}

